\title{
PANORAMA DO PRINCÍPIO DA LEGALIDADE NO DIREITO PENAL ALEMÃO VIGENTE
}

\author{
Nereu José Giacomolli e Pablo Rodrigo Alflen da Silva
}

OVERVIEW OF THE LEGALITY PRINCIPLE IN CONTEMPORARY GERMAN CRIMINAL LAW

\section{RESUMO}

O ARTIGO ANALISA O PRINCÍPIO DA LEGALIDADE PENAL DESDE A PERSPECTIVA ALEMÃ. NesSE SENTIDO, COM BASE EM UM MÉTOdO COMPARADO, DESENVOLVE UM PANORAMA DOS ASPECTOS LEGAIS, DOGMÁTICOS E JURISPRUDENCIAIS RELACIONADOS A ESTE PRINCÍPIO. COM ISSO, TEM POR OBJETIVO PROPORCIONAR AO PÚBLICO BRASILEIRO UMA VISÃO GERAL ACERCA DO PRINCÍPIO, NO QUE DIZ RESPEITO À SUA PREVISÃO LEGAL E À SUA ESTRUTURAÇÃO DOGMÁTICA, TAL COMO DELINEADA PELA LITERATURA JURÍDICOPENAL ALEMÃ, BEM COMO À SUA APLICABILIDADE NO ÂMBITO JUDICIAL ALEMÃo. SOBRETUdO NO TOCANTE A ESTE ÚLTIMO ASPECTO, PRETENDE-SE APRESENTAR O MODELO ALEMĀO COMO UM EXEMPLO A NĀO SER SEGUIDO, FACE A SUA ATUAL ORIENTAÇÃO NO SENTIDO DE FLEXIBILIZAÇÃO DO PRINCÍPIO DA LEGALIDADE.

\section{PALAVRAS-CHAVE}

DIREITO PENAL ALEMÃO; PRINCíPIO DA LEGALIDADE; CódIGO PENAL ALEMÃO.

\section{ABSTRACT}

THE ARTICLE ANALYZES THE PRINCIPLE OF LEGALITY FROM THE PERSPECTIVE OF THE GERMAN CRIMINAL LAW. IN THIS APPROACH, BASED ON A COMPARATIVE METHOD, DEVELOP AN OVERVIEW OF THE LEGAL, DOGMATIC AND JUDICIAL ASPECTS RELATED TO THIS PRINCIPLE. WITH THIS, AIMS TO PROVIDE TO THE BRAZILIAN PUBLIC AN OVERVIEW OF THE PRINCIPLE, SINCE ITS LEGAL BASIS UNTIL ITS DOGMATIC STRUCTURE, AS OUTLINED BY THE GERMAN CRIMINAL LITERATURE, AS WELL AS ITS APPLICABILITY IN THE GERMAN COURTS. PARTICULARLY ON THE LATTER ASPECT, WE INTEND TO PRESENT THE GERMAN MODEL AS AN EXAMPLE NOT BE FOLLOWED, DUE ITS CURRENT ORIENTATION TOWARDS RELAXING THE PRINCIPLE OF LEGALITY.

\section{KEYWORDS}

GERMAN CRIMINAL LAW; PRINCIPLE OF LEGALITY; GERMAN CRIMINAL CODE.

\section{INTRODUÇÃO}

O direito penal alemão, indubitavelmente, sempre exerceu forte influência no desenvolvimento da dogmática jurídico-penal dos países, inclusive para além do mundo europeu. Essa influência ocorreu, apropriadamente, em razão do grande desenvolvimento da dogmática jurídico-penal alemã, o que, notadamente, fez com que o direito penal alemão sempre representasse um paradigma a ser seguido.

Contudo, atualmente, a própria dogmática penal alemã tem se orientado pelos modernos movimentos de política criminal (exemplos disso são os chamados direito penal do risco e do inimigo), os quais, no entanto, possuem como ponto em comum a 
exigência de flexibilização dos princípios penais de garantia e, por conseguinte, o estabelecimento de uma dogmática assentada em estruturas abstratas de punição, em consonância com esses princípios. Um dos princípios é, justamente, o princípio da legalidade penal.

Em razão disso, o presente estudo analisa este princípio, desde a perspectiva alemã, desenvolvendo um panorama dos aspectos legais, dogmáticos e jurisprudenciais relacionados ao mesmo. Por isso, tem por objetivo precípuo proporcionar uma visão geral acerca do postulado, no que pertine à sua previsão legal e à sua estruturação dogmática, tal como delineada pela literatura jurídico-penal alemã, bem como no tocante à sua aplicabilidade no âmbito judicial alemão. Pretendese, ainda, com esta abordagem, evidenciar o fato de que a estrutura legal e dogmática do princípio da legalidade, apresentada de forma secular pela doutrina alemã, como postulado representativo de um Estado de Direito (Rechtsstaatsprinzip), ${ }^{1}$ sofre os influxos dos modernos movimentos político-criminais, de forma a afetar fundamentalmente a estrutura legal como um todo, face às tentativas de sua flexibilização.

\section{ESFORÇO ESCLARECEDOR}

Toda lei penal traduz uma decisão política (político-criminal), ou seja, esta dá origem àquela. Apesar disso, o vínculo existente entre ambas é "quebrado" pelo princípio fundamental da legalidade, de máxima significação à segurança jurídica. $\mathrm{O}$ princípio da legalidade, no âmbito jurídico brasileiro, está descrito no artigo 5..$^{\circ}$, inciso XXXIX da CF/1988 que expressa, in verbis, que "não há crime sem lei anterior que o defina, nem pena sem prévia cominação legal".

No código penal brasileiro, o referido princípio encontra seu embasamento no artigo primeiro, o qual apresenta, substancialmente, a mesma redação do preceito constitucional. Segundo este princípio, uma ação somente pode ser punida quando a punibilidade estiver determinada antes da ação ser perpetrada, ou seja, os pressupostos da punibilidade e as consequências jurídicas do ato precisam estar determinados já na época do fato, através de uma lei.

O princípio da legalidade ou da reserva legal possui uma significação mais ampla do que a simples literalidade ou formalidade do nullum crimen, nulla poena, sine lege, na medida em que a essência do princípio, ou seu aspecto material, a partir do topos hermenêutico constitucional, está na garantia de proteção dos cidadãos, frente à potestade punitiva estatal. Deste princípio se inferem três garantias básicas de direito material: criminal (tipicidade), penal (sanções) e penitenciária (execução penal) e uma processual: jurisdição. Portanto, é o princípio da legalidade que serve de fundamento ao limite da potestade punitiva, como limite do poder político jurídico, mas não dos direitos e das garantias, do status libertatis. ${ }^{2}$ 
Na medida em que na maioria dos Estados democráticos, de matriz codificadora, tal princípio tem encontrado sua respectiva positivação, é conveniente examinar a própria legislação penal de base e sua correspondente evolução para, só assim identificar o grau de adesão da respectiva cultura jurídica a ideia de legalidade penal. Partindo daí, é importante, antes de analisar a previsão do princípio da legalidade na legislação penal alemã vigente, considerar a própria evolução do código penal alemão.

\section{O CÓdigo PENAL AlEMÃo}

O StGB (Código Penal Alemão) de 1975, vigente na Alemanha, não é caracterizado como um código integralmente novo, posto que é resultado de uma reforma profunda e incisiva do RStGB (Código Penal do Reich), de 15.05.1871. ${ }^{3}$ Além disso, formalmente, o StGB tem sido objeto de reformas periódicas e complexas. A última alteração foi em decorrência da Lei de 02.10.2009 (BGBl., I, Nr. 66, de.10.2009). ${ }^{4}$ Portanto, o RStGB, de 1871, foi o primeiro Código da Alemanha unificada e representou uma síntese de dois textos precedentes, a saber, o Código Prussiano de 1851, e o Código Bávaro de 1813.

No que tange especificamente ao seu teor, é entendimento assente na doutrina alemã que o Código de 1871 tem por característica fundamental a constituição de tipos penais formulados de maneira clara e concisa ${ }^{5}$. Apesar disso, Palazzo entende que é difícil negar uma clara linha de continuidade no pensamento e na tradição penalística alemã, sobretudo quando se parte da Constitutio Criminalis Carolina, de 1532 (o ordenamento do imperador Carlos V) ${ }^{6}$, e do Código Bávaro de 1813.7 E isso é compreensível, na medida em que se parte do fato de que a Constitutio Criminalis Carolina deixava o poder de punir, excessivamente, nas mãos do julgador. Apesar de obrigar os órgãos judiciais a atuar conforme determinava a lei, como princípio, também admitia, com uma certa cautela, uma punição extralegal, conforme os "bons costumes". Além disso, permitiu a aplicação analógica a "casos inominados". 8

O código bávaro (o bayerischen StGB), elaborado por Paul Johann Anselm Ritter von Feuerbach, se opunha à concepção instituída na Constitutio Criminalis Carolina e, em virtude disso, representou um dos Códigos mais característicos do direito penal alemão, na medida em que, inclusive, já previa, em seu início, o princípio da legalidade, de acordo com a fórmula apresentada pelo jurista (nulla poena sine lege) ${ }^{9}$. Assim dispunha o $\S 1$ do bayerischen $S t G B$ :

$\S 1$ "Wer eine unerlaubte Handlung oder Unterlassung verschulde, für welche ein Gesetz ein gewissen Uebel gedroht hat, ist diesem gesetzlichen Uebel al seiner Strafe unterworfen". ${ }^{10}$

O preceito, inclusive, refletia a proposição de legalidade cunhada por Feuerbach, em seu Tratado: 
I. Toda inflição de uma pena pressupõe uma lei penal (Nulla poena sine lege).

Pois a pura e simples ameaça do mal através da lei justifica a idéia e a possibilidade jurídica de uma pena. II. A inflição de uma pena está condicionada à existência da conduta ameaçada (Nulla poena sine crimine). Pois através da lei a pena cominada está vinculada ao fato como um pressuposto juridicamente necessário. III. O fato ameaçado legalmente (o pressuposto legal) está condicionado pela pena legal (Nullum crimen sine poena legali). Pois através da lei se vincula à determinada lesão ao direito o mal como conseqüência juridicamente necessária. ${ }^{11}$

Por sua vez, o Código prussiano, de 1851, influenciado pelo Code Napoléon de 1810, e elaborado sob a liderança de Savigny ${ }^{12}$, era considerado uma típica expressão do pensamento jurídico da primeira metade dos anos oitocentos, com uma clara característica conservadora, além de orientar-se pela ideia de prevenção geral da pena (punição exemplar). Contudo, reportava-se a uma figura de pessoa humana um pouco abstrata, condicionável a processos motivacionais, mediante a aplicação da pena, típica de uma sociedade mecanicista. ${ }^{13}$

O RStGB, de 1871, portanto, registra uma fusão de dois modelos. Compreende um texto de matriz clássica, no qual a ideia de retribuição surge conjuntamente com a de prevenção geral e com poucas referências à prevenção especial. Este Código se insere no movimento codificador e reflete a tendência nacionalista que acompanhava a unificação dos grandes Estados nacionais. Pode-se dizer que se deve às boas experiências de codificações penais, nas quais a legislação alemã já demonstrava tons de perfeição técnica. Porém, manteve certa distância entre suas normas e a realidade econômico-social da nação, caracterizada principalmente ao final do século XIX, por grandes e rápidas mudanças. ${ }^{14}$

Apesar disso, como refere Peter-Alexis Albrecht, na criação do RStGB, de 1871, tinha-se por base a ideia de Estado de Direito e de Constituição, tanto que o $§ 2$ deste Código trazia em seu bojo o mesmo teor do Art. 103, 2 da atual Lei Fundamental (GG), que justamente prevê o princípio da legalidade.

Mas nos primeiros anos do século XX este código foi objeto de projetos de reforma, sobre os quais, inclusive, se confrontaram a escola clássica de Karl Binding e a escola moderna de Franz von Liszt (que no Marburger Programm - 1882 - difunde novamente a ideia de prevenção especial, fundada sobre aspectos empíricos e sobretudo sociais da política criminal). Em 1911, Karl Stoos apresenta, por sua vez, um projeto de reforma que prevê o retorno do sistema do "doppio binario" como ponto de mediação entre as duas escolas. Porém, um projeto de reforma, particularmente inovador, foi apresentado em 1922, por Gustav Radbruch (que, à época, além de insigne penalista e filósofo, era Ministro da Justiça). Tal projeto foi considerado, no entanto, muito audaz para ser aprovado. 
Apesar das insuficiências e das reformas, o Código de 1871 sobreviveu, mesmo após o advento do regime nazista, o qual estabeleceu uma série de leis especiais que deturparam os clássicos princípios de garantia do direito penal, registrandose, inclusive, a aplicação da pena de morte a alguns crimes. No entanto, no período pós-guerra as maiores barbáries recaíram nas fontes do direito penal, pois, de um lado, afirmou-se o princípio da analogia in malam partem e, de outro lado, abriram-se, decisivamente, as fontes extralegais como, por exemplo, a ideia de são sentimento do povo, assim como interpretava o Führer (e instituída no direito penal alemão por Edmund Mezger, em sua obra Deutsches Strafrecht ${ }^{15}$ ). De outra sorte, instituiu-se um vasto e penetrante sistema de polícia que, de fato, substituiu o rígido direito penal.

É oportuno referir aqui a figura de James Goldschmidt que, em sua tese de habilitação intitulada “o direito penal administrativo", discutia a respeito das assim denominadas violações (Übertretungen ${ }^{16}$ ), que ainda eram reguladas juntamente com crimes e delitos no Código Penal do Império. Goldschmidt se manifestava pela delimitação entre as violações e os fatos puníveis propriamente ditos e pela conversão do direito das violações em direito administrativo. ${ }^{17}$

O Código de 1871, no entanto, permaneceu em vigor, sendo que no período pós-guerra, com o cancelamento das legislações instituídas pelo delírio nazista, foi aprovada, em 1949, a Grundgesetz, isto é, a nova lei fundamental da República Federal Alemã (RFA). ${ }^{18}$ Palazzo $^{19}$ refere que ela não era propriamente uma Constituição (pois só se pode falar em tal após a reunificação do povo alemão), mas sim uma lei de categoria superior, na qual se consagram formalmente muitos princípios de garantia que interessam diretamente ao direito penal, tais como: a abolição das penas de morte (art. 102); respeito ao princípio da legalidade (art. 103, 2) com uma formidável sinteticidade que conduziu a um extraordinário desenvolvimento na doutrina e na jurisprudência, do seu corolário de certeza e determinação; a afirmação solene (ao final do primeiro artigo) da dignidade humana como princípio irrenunciável, absoluto e fundante da ideia de direito.

Com a entrada em vigor da Lei Fundamental alemã se registram pressões direcionadas à reforma do StGB. Não só porque o código vigente teria mais de um século de existência, mas pela necessidade de reafirmar em um texto legislativo, de maneira profunda e organicizada, os valores e princípios fundamentais, em face da barbárie que teria representado o nazismo. ${ }^{20}$

Ao final dos trabalhos de uma comissão ministerial, que se reuniu de 1954 a 1959, foi apresentado, em 1962, um projeto de lei orgânica de reforma (o Entwurf 1962 - E 1962), relativo somente à parte geral do Código Penal. Tratava-se de um projeto tecnicamente bem aquilatado, que reelaborava e reassumia todo o desenvolvimento científico a partir de 1871, com notável precisão dogmática, mas que, antes de tudo, se caracterizava fortemente por dois aspectos: ${ }^{21}$ 
(1) Face à orientação pela legalidade, tinha uma forte propensão ao estabelecimento de definições já nas próprias normas. Porém, caso as definições se revelassem eficazes, poderiam conduzir a um bloqueio do pensamento científico, da elaboração doutrinária e jurisprudencial, justificada pelo "ótimo dado positivo" e, se ineficazes, poderiam criar inúmeras confusões, desacreditando as fontes codificadoras do direito penal, acentuando as discussões da doutrina e da jurisprudência, conduzindo a uma substancial incerteza das normas.

(2) Apresentava um traço altamente eticizante, marcantes da história e da tradição alemã, em particular da ideia retributiva da pena, enunciadora de uma visão ética do direito penal.

Klaus Volk, aliás, teceu críticas incisivas ao E 1962, referindo que, no tocante ao sistema de sanções, ele era muito progressista e orientado, de forma evidente, por um pensamento retributivo. Ademais, o projeto estava muito longe dos modernos princípios político-criminais de proteção dos bens jurídicos e da subsidiariedade do direito penal. O conceito de crime, que era a base deste projeto, estava orientado por concepções jusnaturalistas e ontologizadas. O que não poderia ser diferente posto que neste momento o finalismo tinha atingido o seu auge na Alemanha.

Em reação ao E 1962, um grupo de juristas alemães apresentou, em 1966, o Alternativ Entwurf (AE 1966), um projeto alternativo de reforma, publicado em três volumes. O projeto refutava a ideia retributiva e de inspiração eticizante, aderia completamente à orientação preventiva especial, estabelecia um novo impulso no sistema de penas, com inúmeras hipóteses de medidas alternativas. A culpabilidade era estabelecida como limite das garantias invioláveis do sistema sancionatório e não como fundamento justificador da pena. ${ }^{22}$

Com isso, em 1969, o Bundestag aprovou as duas primeiras leis de reforma: a primeira, destinada a entrar rapidamente em vigor, prevendo uma série de alterações urgentes na parte especial; a segunda, de fundamental importância, apresentava uma radical modificação na parte geral do código, destinada a entrar em vigor após uma longa vacatio legis (de seis anos). O código entrou em vigor em 01 de janeiro de 1975.

Contudo, em consonância com as opções político-criminais que orientavam o $A E$ 1966, com a abolição da categoria de ilícitos penais contravencionais e a redução a somente aqueles que são de relevância penal, foi aprovada outra grande operação de reforma, promulgando uma lei de com grande conteúdo despenalizador, que estabeleceu uma nova e orgânica disciplina dos ilícitos administrativos (idealizada por Goldschmidt ${ }^{23}$ ). À área dos ilícitos administrativos foram destinados grande parte dos ilícitos antes previstos como contravenções, tendo-se criado, a partir daí, a OWiG (Lei dos ilícitos à ordem). 
No início da década de 1970 o legislador alemão criou a "Lei de introdução ao código penal” (EGStGB), que continha uma série de dispositivos de caráter geral (mais especificamente, 326 artigos) que diziam respeito ao âmbito de validade do código penal, disposições comuns, a adaptação das normas penais e modificações no código penal. O fluxo legislativo manteve-se intenso, tendo havido leis relativamente à criminalidade ambiental e econômica, à dita criminalidade organizada, bem como, em janeiro de 1998, uma reforma de conteúdo heterogêneo, denominada de VI Grande Lei da Reforma, contendo três aspectos da parte especial: numeração de hipóteses incriminadoras, ampliação da previsão para alguns delitos e definição do dolo específico nos crimes patrimoniais. ${ }^{24}$

A característica fundamental da parte geral do StGB, como que radicalmente renovado em 1975, compreende três grandes núcleos temáticos: (a) fontes do direito penal, (b) os pressupostos da responsabilidade penal e (c) o sistema de sanções.

\section{O PRINCÍPIO dA LEGAlidAde NO DiReito PENAl Alemão}

Após esta breve incursão de matiz histórico-evolutivo acerca do Código Penal alemão, verifica-se que a ideia de legalidade sempre esteve presente no ordenamento alemão, embora em determinado período tenha sofrido os influxos de um regime autoritário típico de um Estado de Polícia, representado pelo Nazismo. Nesse sentido, cumpre analisar a legislação alemã vigente e a respectiva positivação do princípio da legalidade para, então, por conseguinte, proceder ao exame da estruturação dogmática do princípio.

\section{I. Previsão na legislação alemã vigente}

Como analisado, e inclusive ressaltado por Hassemer, o princípio da legalidade, sob a ótica legiferante, nasceu com o Code Pénal, de 1810, e chegou ao RStGB de 1871 por meio do Código Prussiano, de 1851. No plano constitucional foi a Constituição de Weimar quem conferiu ao princípio da legalidade a categoria constitucional, ao inseri-lo em seu artigo 116. A partir daí, foi transferido para a Lei Fundamental, encontrando seu embasamento no atual artigo 103, $2 .{ }^{25}$

O direito penal alemão vigente prevê o princípio da legalidade no $\S 1$ do StGB e no artigo 103 da GG. O $\S 1$ do StGB dispõe, na esteira do proposto por Feuerbach em seu famigerado Tratado, ${ }^{26}$ expressamente:

$\S 1$ Keine Strafe ohne Gesetz: Eine Tat kann nur bestraft werden, wenn die Strafbarkeit gesetzlich bestimmt war, bevor die Tat begangen wurde. ${ }^{27}$

Por sua vez, o artigo 103, 2, da GG, dispõe o princípio da legalidade exatamente com a mesma redação, conforme se verifica do teor do dispositivo: 
Art. 103, 2: Eine Tat kann nur bestraft werden, wenn die Strafbarkeit gesetzlich bestimmt war, bevor die Tat begangen wurde. ${ }^{28}$

É oportuno referir ainda que o mesmo dispositivo da Constituição alemã, na alínea 3, consagra o princípio "ne bis in idem" (proibição da dupla punição) expressamente:

Art. 103, 3: Niemand darf wegen derselben Tat auf Grund der allgemeinen Strafgesetze mehrmals bestraft werden. ${ }^{29}$

O princípio da legalidade, no entanto, foi estendido inclusive ao âmbito dos ilícitos administrativos, previstos na OWiG, conforme dispõe o $§ 3$ :

§ 3: Keine Ahndung ohne Gesetz: Eine Handlung kann als Ordnungswidrigkeit nur geahndet werden, wenn die Möglichkeit der Ahndung gesetzlich bestimmt war, bevor die Handlung begangen wurde. ${ }^{30}$

\subsection{O REGIME CONSTITUCIONAL DA CONCORRÊNCIA LEGISLATIVA EM MATÉRIA PENAL}

Há que ser observado o fato de que a Lei fundamental da República Federal da Alemanha prevê a competência da Federação e dos $L a ̈ n d e{ }^{31}$ para legislar em matéria penal. A Reichsverfassung (Constituição do Império Alemão) de 16 de abril de $1871^{32}$ sinalizou a mudança para uma federação com competência geral e não pela reunião das meras competências dos estados singulares. O próprio preâmbulo da Reichsverfassung ressaltava que a competência do Império não podia ser desviada para os estados individuais. Contudo, as competências indicadas pela legislação nas disposições isoladas da Constituição do Império autorizavam que se recorresse à administração, sendo que pela lei de reforma constitucional posterior se possibilitou a transferência das competências aos Länder. ${ }^{33}$

Isso foi uma decorrência da diferenciação entre a competência exclusiva e facultativa atribuída ao Império, e da qual resultou a idéia de "konkurrierende Zuständigkeit" (competência concorrente), inclusive em matéria penal. A concorrência legislativa prevista no artigo 74, 1 da GG, apesar de não excluir a possibilidade do Estado se reserva à produção legislativa (art. 77, 2 GG), autoriza e legitima o recurso à denominada técnica das leis penais em branco, pois o artigo 80, 1 da GG estabelece que os Länder podem ser autorizados através de lei federal a emitir decretos, embora a lei deva determinar o conteúdo, objetivo e extensão da autorização outorgada. As regras principais encontram-se na Lei de Introdução ao StGB (art. 1-4 EGStGB). ${ }^{34}$

Assim dispõe o art. 74, 1, da GG:

Art. 74: Die konkurrierende Gesetzgebung erstreckt sich auf folgende Gebiete: 1. das bürgerliche Recht, das Strafrecht und den Strafvollzug, die Gerichtsverfassung, das gerichtliche Verfahren, die Rechtsanwalt, das Notariata und die Rechtsberatung. ${ }^{35}$ 
Palazzo ressalta, no entanto, que esta concorrência legislativa entre a Federação e os Länder conduz a uma dupla ordem de limites. O primeiro limite recai no artigo 72, 1 da GG, cujo preceito estabelece o princípio da subsidiariedade da legislação dos Länder em face da legislação federal, posto que:

Art. 72, 1: Im Bereiche der konkurrierenden Gesetzgebung haben die Länder die Befugnis zur Gesetzgebung, solange und soweit der Bund von seinem Gesetzgebungsrechte keinen Gebrauch macht. ${ }^{36}$

Agora, o segundo limite decorre dos artigos 1 a 4 da EGStGB (Lei de Introdução ao Código Penal). Isso porque o artigo $1 .^{\circ}$ estabelece que a parte geral do Código vale incondicionalmente para o direito penal dos Länder e isso assume reflexos no que diz respeito à previsão do artigo 2, que determina, portanto, que o direito penal regional (dos Länder) pode prever para os seus ilícitos limites espaciais diversos daqueles estabelecidos no código penal. É possível prever causas particulares de não punibilidade, mais amplas do que as previstas no direito penal federal.

Ademais, o artigo 3 da EGStGB proíbe a cominação de penas privativas de liberdade superiores a dois anos e de penas pecuniárias superiores ao máximo dos limites previstos no StGB. Já o artigo 4 secunda o princípio da subsidiariedade na concorrência legislativa, ressaltando que quando o legislador federal silenciar, intencionalmente, no tocante à intervenção penal, o legislador regional não pode incriminar os comportamentos penalmente lícitos pela vontade do legislador federal.

Palazzo entende que esta série de limites apenas ilustra o modesto papel dos Länder na experiência legislativa penal da Alemanha. Contudo, não nos parece ser tão modesto o papel, posto que é justamente esta espécie de concorrência legislativa que torna absolutamente admissível, por exemplo, o emprego de leis penais em branco. De outra sorte, se comparado rigorosamente com o modelo brasileiro, o emprego desta técnica seria absolutamente proscrito.

Nesse sentido, inclusive, manifestou-se recentemente o tribunal constitucional federal alemão:

Art. 103 Abs. 2 GG erfasst insbesondere Straf- und Bußgeldtatbestände (vgl. BVerfGE 81, 132 135; 87, 399 411). Legt eine Sanktionsnorm - wie § 15 Abs. 1 Nr. 4 LImSchG Blndas bewehrte Verhalten nicht selbst fest, sondern verweist sie auf eine verwaltungsrechtliche Vorschrift, müssen beide Vorschriften in ihrer Gesamtheit sowie ihre Auslegung und Anwendung im Einzelfall den verfassungsrechtlichen Vorgaben des Art. 103 Abs. 2 GG genügen (vgl.zu derartigen „Blanketttatbeständen “ BVerfGE 75, 329340 ff.; 87, 399 407; Schmidt-Aßmann, in: Maunz/Dürig, GG, Art. 103 Abs. 2 GG, Rn. 208 Bearbeitungsstand Dezember 1992). ${ }^{37}$ 
Estabelecida a previsão legal e os limites da concorrência legislativa, passaremos a tratar dos postulados da legalidade, sob a perspectiva da dogmática alemã.

\subsection{Os Postulados da legalidade Penal Sob a Ótica dA dogmática Alemã}

O princípio da legalidade, conforme entendimento assente na doutrina alemã é típica expressão da ideia de Estado de Direito e determina que este há de proteger o indivíduo não só por meio do Direito Penal, como também em face do direito penal. Em outras palavras, a ordem jurídica deve não só colocar à disposição métodos e meios adequados de prevenção do crime, como também, nas palavras de Roxin, impor limites ao poder de punir do "Estado Leviatã". 38

Na República Federal da Alemanha, como visto, o âmbito de aplicação do princípio da legalidade foi estendido aos ilícitos administrativos (§ 3. OWiG), autorizando inclusive "incriminação" por parte de fontes subprimárias das autoridades centrais e periféricas.

Conforme Jakobs, ${ }^{39}$ e aqui o jurista alemão segue a doutrina alemã em sua totalidade, a lei no sentido do princípio da legalidade é toda norma jurídica escrita, quer se trate de uma lei formal, um regulamento ou decreto. Contudo, ressalta que se deve ter em vista que o artigo 104, 1 da GG estabelece que somente por lei formal pode ser imposta pena privativa de liberdade.

Mutatis mutandis, é entendimento comum o de que a generalização da formação da lei penal determina um risco à segurança jurídica, porque pode ser produzida por meio da vinculação excessiva a cláusulas gerais, objetivamente distintas, que anulam a função de garantia da lei penal. ${ }^{40}$

Assim, através do princípio da legalidade realiza-se a função de garantia da lei penal ${ }^{41}$ como uma "Magna Charta Libertatum do Cidadão", 42 hoje reconhecido, na doutrina alemã, por seus quatro desdobramentos: ${ }^{43}$

- a fundamentação da pena e o agravamento não podem realizar-se por meio do Direito consuetudinário (lex scripta);

- a impossibilidade de aplicação analógica da lei penal (lex stricta);

- a irretroatividade da lei penal (lex praevia);

- a lei penal deve ser precisa, ou seja, seu conteúdo e limites devem ser definidos, na medida do possível, pelo próprio texto de lei (lex certa). ${ }^{44}$

Jescheck adverte que os dois primeiros dirigem-se ao juiz e os últimos ao legislador, pois o grau de vinculação do juiz à lei é determinado pelo grau de exatidão com que a vontade comum é expressa na lei. ${ }^{45}$ Nesse sentido, como afirma Hassemer, o juiz, na sentença, não tem outra tarefa senão a de concretizar o conteúdo da lei sobre o caso, em decisão, pois a vinculação do juiz à lei é obrigatória, ${ }^{46}$ embora, com razão, entenda que o princípio da legalidade vincula o juiz tanto pela proibição da analogia 
e da fundamentação e agravamento da pena pelo direito consuetudinário, como também pela proibição da retroatividade. ${ }^{47}$

\subsection{Panorama jurisprudencial e Perspectiva crítica}

Palazzo refere que o direito penal alemão tem atribuído amplo espaço operativo aos costumes e à analogia, sobretudo em termos de causas de justificação. Assim, refere que, justamente em razão disso, as causas de justificação previstas na parte geral do código penal são poucas, restringindo-se à legítima defesa (§ 32) e ao estado de necessidade ( $(34)$. O próprio consenso está previsto, de forma direta, como excludente especial dos crimes ( $\$ 228$ do $\mathrm{StGB}^{48}$ ).

Contudo, chama a atenção quanto ao uso de um procedimento muito comum na legislação alemã, considerado hipótese de analogia. Trata-se do uso da regra exemplificativa (Regelbeispiele), segundo a qual o legislador formula uma norma substancialmente aberta, elencando uma série de hipóteses. O exemplo que Palazzo aponta é o do $\S 243$ do StGB, o qual tipifica o furto de particular gravidade. Entende Palazzo que, no caso deste delito, o legislador, ao elencar os exemplos, autoriza a interpretação analógica.

Aliás, isso é corroborado por Roxin (assim como por Jescheck) ${ }^{49}$ ao tratar das regras exemplificativas, o qual ressalta que nestes casos o juiz poderia aceitar a aplicação da norma quando houvesse um exemplo mais gravoso, assim como ele, ao contrário, poderia afirmar um caso particularmente grave, apesar de não haver um exemplo legal.

Mas, justamente por questões como estas, que Albrecht tem apontado a Alemanha, atualmente, como um referencial negativo. Nesse sentido refere o autor que, prescindindo dos postulados da legalidade, "o legislador cria tipos penais que, mesmo para os versados, não são mais compreensíveis. Tipos nos quais mal parece possível distinguir a conduta punível de uma conduta cotidiana normal”. ${ }^{50}$

Na jurisprudência alemã, sobretudo do BVerfG (Tribunal Constitucional Federal), o princípio da legalidade é amplamente utilizado. Porém, muitas decisões têm considerado legítimos os preceitos extremamente genéricos. Assim, por exemplo, é a decisão do BVerfG 1 BvR 2150/08, 2-3:

Die Vorschrift des $\S 130$ Abs. 4 StGB wurde mit dem Gesetz zur Änderung des Versammlungsgesetzes und des Strafgesetzbuchs vom 24. März 2005 in das Strafgesetzbuch eingeführt und trat mit Wirkung zum 1. April 2005 in Kraft (BGBI I S. 969 970). Sie lautet:

(4) Mit Freiheitsstrafe bis zu drei Jahren oder mit Geldstrafe wird bestraft, wer öffentlich oder in einer Versammlung den öffentlichen Frieden in einer die Würde der Opfer verletzenden Weise dadurch stört, dass er die nationalsozialistische Gewalt- und Willkürherrschaft billigt, verherrlicht oder rechtfertigt. 
Schließlich laufe § 130 Abs. 4 StGB nicht dem Bestimmtheitsgebot des Art. 103 Abs. 2 GG zuwider. Sämtliche Tatbestandsmerkmale seien entweder aus sich selbst heraus oder aus dem Zusammenhang mit anderen Bestimmungen des Strafgesetzbuchs, wo sie bereits eine Konkretisierung erfahren hätten, hinreichend bestimmbar. ${ }^{51}$

Na decisão referida, apesar da total generalidade do preceito, entendeu o Tribunal Constitucional Federal que não há violação à exigência de certeza da lei penal. Daí dizer Albrecht que a jurisprudência não tem corrigido estes problemas. Ao contrário, o Tribunal Constitucional Federal e o Supremo Tribunal Federal alemães acentuam, cada vez mais, a grande margem que o legislador tem na formulação das leis penais". ${ }^{52}$

Nesse sentido, o Tribunal Constitucional Federal ${ }^{53}$ tem entendido que as leis penais devem ser elásticas (flexíveis), para poder abarcar a multiformidade da vida:

Art. 103 Abs. 2 GG verpflichtet den Gesetzgeber, die Voraussetzungen der Strafbarkeit so konkret zu umschreiben, dass Anwendungsbereich und Tragweite der Straftatbestände sich aus dem Wortlaut ergeben oder jedenfalls durch Auslegung ermitteln lassen. Das schließt allerdings nicht eine Verwendung von Begriffen aus, die in besonderem Maß der Deutung durch den Richter bedürfen. Auch im Strafrecht steht der Gesetzgeber vor der Notwendigkeit, derVielgestaltigkeit des Lebens Rechnung zu tragen. Ferner ist es wegen der Allgemeinheit und Abstraktheit von Strafnormen unvermeidlich, dass in Einzelfällen zweifelhaft sein kann, ob ein Verhalten noch unter den gesetzlichen Tatbestand fällt oder nicht. Jedenfalls im Regelfall muss der Normadressat aber anhand der gesetzlichen Vorschrift voraussehen können, ob ein Verhalten strafbar ist. In Grenzfällen ist auf dieseWeise wenigstens das Risiko einer Bestrafung erkennbar (stRspr, vgl. BVerfGE 92, 1 12). ${ }^{54}$

Isso, nas palavras de Albrecht, tem contribuído, decisivamente, para que o direito penal passe a ser pautado e caracterizado por uma série de conceitos jurídicos indeterminados. Ademais, os chamados delitos de perigo, sobretudo de perigo abstrato - que envolvem a legislação de trânsito, ambiental e o direito penal econômico -, que eram considerados exceção no plano legiferante, passaram a ser regra. Isso tem produzido uma antecipação da punibilidade. ${ }^{55}$ É nesse sentido que o jurista tem referido, ainda, que os postulados clássicos do princípio da legalidade, que formam a base do direito penal do Estado de direito, na práxis, têm se apresentado como um ideal irrealizável, um ideal que se pode esquecer no caso do cidadão cair nas mãos do direito penal. 56

\section{CONCLUSÃo}

O princípio da legalidade no direito penal alemão, sob o ponto de vista de sua previsão legal, segue uma larga tradição. Pode-se dizer que o legislador alemão sempre 
considerou a ideia de legalidade como um primado de garantia, no sentido de que a sua previsão legal consolida o seu status como horizonte sobre o qual se projeta a estrutura dogmática do direito penal alemão. Já, sob este aspecto, o dogmático, a doutrina alemã tem apontado, como postulados fundamentais do princípio da legalidade, os seguintes: (a) a fundamentação da pena e o agravamento não podem realizar-se por meio do direito consuetudinário (lex scripta); (b) a impossibilidade de aplicação analógica da lei penal (lex stricta); (c) a irretroatividade da lei penal (lex praevia); e d) a lei penal deve ser precisa, ou seja, seu conteúdo e limites devem ser definidos, na medida do possível, pelo próprio texto de lei (lex certa).

No entanto, o desenvolvimento legislativo no âmbito alemão e a praxis judicial têm caminhado em sentido diverso, isto é, no sentido da flexibilização do princípio da legalidade, na medida em que abdica dos postulados básicos que asseguram a liberdade do cidadão. Em face disso, descortina-se um paradoxo no tocante ao fato de que a cultura que consolidou o princípio da legalidade como "espinha dorsal" do direito penal e, sobretudo, como garantia da liberdade do cidadão, atualmente olvida o que há muito já fora referido por Engisch de que "somente sob o jugo do Estado totalitário aprende o homem a apreciar de novo os perdidos direitos e liberdades fundamentais." 57

: ARTIGO APROVADO (07/10/2010) : RECEBIDO EM 12/04/2010

NOTAS

1 Assim, compare Rudolphi/Horn/Samson/Schreiber. Systematischer Kommentar zum Strafgesetzbuch. § 1, I, 1, p. 23; no mesmo sentido JESCHECK. Lehrbuch des Strafrechts. § 15, p. 76; compare, ainda, Alflen da Silva, Pablo Rodrigo. Leis penais em branco e o Direito Penal do Risco. RJ: Lumen Juris, 2005, p. 141 e s.

2 GiACOMOLLI, Nereu José. "O princípio da legalidade como limite do ius puniendi e proteção dos direitos fundamentais” em STRECK, L. L. (Org.). Direito penal em tempos de crise. Porto Alegre: Livraria do Advogado, 2007, pp. 151-166, as origens e os antecedentes do princípio da legalidade, sua delimitação conceitual, seus fundamentos, bem como seus efeitos e garantias (nas fontes do direito penal, no processo tipificador e na individualização da pena).

3 PALAZZO, Francesco; PAPA, Michele. Lezioni di Diritto Penale comparato. Torino: Giappichelli Editore, 2005, pp. 59-60.

4 Tal Lei procedeu unicamente à supressão de breve trecho do $§ 56 \mathrm{~g}$, Absatz 2, Satz 1, do StGB.

5 Assim ROXIN, Claus. Strafrecht. Allgemeiner Teil, Bd. I, 1992, p. 50. 
6 A “Constitutio Criminalis Carolina”, expressão latina que caracteriza o Peinliche Gerichtsordnung (Ordenamento Judicial Penal), continha, segundo Maurach e Zipf, tanto regras processuais penais como penais materiais e representava uma síntese da tradicional forma de pensar alemã com o novo direito; compare MAURACH, Reinhart; ZIPF, Heinz. Strafrecht. Allgemeiner Teil, Bd. I, 1977, p. 52; a respeito disso veja ainda HAFT, Fritjof. Strafrecht, Allgemeiner Teil, 9. Aufl., p. 30.

7 PALAZZO, Francesco; PAPA, Michele. op. cit., p. 60.

8 ROXIN, Claus. Derecho penal, parte general. Madri: Civitas, 1999, p. 141.

9 Conforme ALBRECHT, Peter-Alexis. Die vergessene Freiheit. Strafrechtsprinzipien in der europäischen Sicherheitsdebatte. 2003, p. 54.

10 Quem comete uma ação ou omissão não permitida, para a qual uma lei cominou um determinado mal, estará sujeito a este mal legal como sua pena", o preceito é citado por ALBRECHT, Peter-Alexis. op. cit.,, p. 178, nota de rodapé 51 .

11 FEUERBACH, Paul Johann Anselm von. Lehrbuch des gemeinen in Deutschland gültigen peinlichen Rechts. 2. Aufl., Gießen: G. F. Heyer, 1803, p. 20.

12 Conforme JESCHECK, Hans-Heinrich. Lehrbuch des Strafrechts, 1977, p. 76.

13 PALAZZO, Francesco; PAPA, Michele. op. cit., p. 60.

14 PALAZZO, Francesco; PAPA, Michele. op.cit., p. 61.

15 Assim MEZGER, Edmund. Deutsches Strafrecht, Ein Grundriß, 3. Aufl., 1943, p. 28 e s., que, tendo por base o $\S$ 2. ${ }^{\circ}$ do StGB à época, referia que "um fato é punido quando a lei o declara como punível ou quando, de acordo com a ideia fundamental de uma lei penal e de acordo com o são sentimento, ele merece punição.”

16 Hoje chamadas violações à ordem e que são reguladas por legislação específica, a "Ordnungswidrigkeitengesetz" (OWiG).

17 Assim o interessantíssimo trabalho intitulado "Conceito e tarefa de um direito penal administrativo", onde Goldschmidt preconizava ser o Direito Penal Administrativo uma disciplina nova e absolutamente autônoma, que teria por objeto regular o "injusto policial" (polizeilichen Unrechts) enquanto comportamento causador de "perigo abstrato para bens jurídicos" ou "mera desobediência”, compare GOLDSCHMIDT, James. Begriff und Aufgabe eines Verwaltungsstrafrechts. In: Deutsche Juristen-Zeitung, 1902, Nr. 09, p. 213 e s. Compare, sob a perspectiva processual LOPES JúNIOR, Aury; ALFLEN DA SILVA, Pablo Rodrigo. Breves apontamentos in memoriam a James Goldschmidt e a incompreendida concepção de processo como 'situação jurídica', Revista de Processo, n. ${ }^{\circ}$ 176, Out. 2009, p. 349 e ss.

18 Um panorama aprofundado sobre a evolução da legislação penal alemã em: BAUMANN, Jürgen. Strafrecht. Allgemeiner Teil, 3. Aufl., 1964, p. 36 e ss.; também em ROXIN, Claus. Strafrecht. Bd. 1., p. 50 e ss.

19 Conforme PALAZZO, Francesco; PAPA, Michele. op. cit., p. 62.

20 Conforme PALAZZO, Francesco; PAPA, Michele. op. cit., p. 62.

21 Conforme PALAZZO, Francesco; PAPA, Michele. op.cit., p. 62 e 63

22 PALAZZO, Francesco; PAPA, Michele. op. cit., p. 63.

23 Vide supra, nota de rodapé 17.

24 Em PALAZZO, Francesco; PAPA, Michele. op. cit., p. 64. Uma das críticas feitas, segundo estes autores, na mesma página, diz respeito ao critério de proporcionalidade adotado ao equilíbrio penológico entre os delitos patrimoniais e os contra as pessoas. A harmonia foi obtida com a elevação das penas. 
25 Compare HASSEMER, Winfried. Einführung in die Grundlagen des Strafrechts, 2. Aufl., 1990, p. 252 (há tradução portuguesa, de Pablo Rodrigo Alflen da Silva, sob o título "Introdução aos fundamentos do direito penal", Porto Alegre: safE, 2005).

26 Conforme ALBRECHT, Peter-Alexis, op. cit., p. 54.

27 "Não há pena sem lei: um fato somente pode ser punido se a punibilidade estiver determinada antes do seu cometimento".

28 Vide supra, nota de rodapé 27.

29 "Ninguém pode ser punido mais de uma vez pelo mesmo fato e com base na mesma lei penal comum."

30 "Não há ameaça sem lei: uma conduta somente pode ser punida como ilícito administrativo, quando a possibilidade de ameaça estiver determinada legalmente antes da ação ser praticada”.

31 Os "Länder" são considerados como parte própria dos Estados Federados, não derivados da Federação, senão reconhecidos a partir dela, acerca disso compare VOGEL, Hans-Joachim. "Die bundesstaatliche Ordnung des Grundgesetzes”, in: MAIHOFER, Werner et al. Handbuch des Verfassungsrechts. Teil Zwei. S. 1054 ff.

32 Convém observar que, pelos tratados de novembro de 1870, houve a recepção dos estados do sul (os “süddeutschen Staaten", compostos por Baden, Württemberg, Hessen e Bayern) ampliando a Federação alemã do norte ("Norddeutschen Bund") com a criação da Federação alemã ("Deutschen Bundes"), à qual logo foi atribuído o título de Império (Reich). Contudo, para unificar o Direito constitucional do Reich, atribuindo-lhe inclusive a própria designação "Império", era necessário que as leis constitucionais do mesmo fossem unificadas em um único documento, que culminou com a Constituição do Império (Reichsverfassung) de 1871. Paradigmático acerca disso STERN, Klaus. Das Staatsrecht der Bundesrepublik Deutschland, Bd. V, p. 333 e ss. Por outro lado, o próprio Código Penal do Império (1871) não foi uma nova criação, mas tão somente ampliou-se a vigência do Código Penal da Federação alemã do Norte aos estados do sul, sobre isso comparar JESCHECK, Hans-Heinrich. Lehrbuch des Strafrechts. p. 76.

33 Comparar com detalhes STERN, Klaus. Das Staatsrecht der Bundesrepublik Deutschland, Bd. V, p. 364, de modo mais preciso VOGEL, Hans-Joachim. Die bundesstaatliche Ordnung des Grundgesetzes. in: MAIHOFER, Werner, et al. Handbuch des Verfassungsrechts. Teil Zwei. p. 1054 e ss, referindo que os Lander são como parte própria dos Estados Federados, não derivados da federação, mas reconhecidos a partir dela.

34 Sobre isso, com detalhes, BLEI, Hermann. Strafrecht. Allg. Teil. 12 Auf., S. 1 ff.

35 "Art. 74. A legislação concorrente restringe-se as seguintes matérias: 1. ao direito civil, ao direito penal e execução penal, a constituição e o procedimento judicial, a advocacia, o notariado e a consultoria jurídica”.

36 Art. 72, 1. No âmbito da legislação concorrente os Estados tem competência para legislar até que a Federação não faça uso de seu direito de legislar”.

37 "O Art. 103, Alínea 2 da Lei Fundamental abarca principalmente tipos penais e de multa (compare as decisões do BVerfG, 81, 132, 135; 87, 399 411). Em uma norma de sanção - como a do $§ 15$, alínea 1, n. ${ }^{\circ} 4$ da LImSchG Bln que não especifica a conduta valorada, senão remete a um preceito administrativo, devem ambos os preceitos, em sua totalidade, bem como a sua interpretação e aplicação ao caso concreto, satisfazer a exigência constitucional do Art. 103, alínea 2 da GG (compare sobre „tipos em branco“ desta espécie as decisões do BVerfG 75, 329340 e ss.; 87, 399 407; Schmidt-Aßmann, in: Maunz/Dürig, GG, Art. 3, Abs. 2 GG, Rn. 208 Bearbeitungsstand Dezember 1992).

38 Compare ROXIN, Claus, Strafrecht..., p. 67; assim também STRATENWERTH, Günter; KUHLEN, Lothar. Strafrecht, Allgemeiner Teil, 2004, p. 42, referindo que desde Locke e Montesquieu o exercício do poder estatal, e também o do juiz, encontra-se estritamente vinculado à lei.

39 Compare JAKOBS. Derecho Penal. p. 88; no mesmo sentido, ALBRECHT, Peter-Alexis. op.cit., p. 48.

40 Comparar JESCHECK. Lehrbuch des Strafrechts. § 15, I, 3, p. 76. 
41 Sobre isso compare a decisão do BVerfG (Tribunal Constitucional Federal) 25, 269 (272) de 26 de fevereiro de 1969; compare ainda JESCHECK. Lehrbuch des Strafrechts. § 15, p. 77; paradigmático SCHÖNKE/SCHRÖDER/ESER. StGB. Kommentar. § 1, I, 3, p. 26.

42 Compare, ainda, HASSEMER, Winfried. op. cit., p. 252; mencionando von Liszt e sua referência ao Código Penal como a "Magna charta do delinquente" veja STRATENWERTH, Günter; KUHLEN, Lothar, op. cit., p. 46. Porém, desenvolvendo uma brilhante paráfrase, veja NAUCKE, Wolfgang. Strafrecht. Eine Einführung, 2002 , p. 68.

43 Paradigmático a respeito GROPP, Walter. Strafrecht, Allgemeiner Teil, 3. Aufl., 2005, p. 55-65; expressamente nesse sentido, compare HASSEMER, Winfried. Op.cit., p. 254; ademais, OTTO, Harro, Grundkurs Strafrecht, Allgemeine Strafrechtslehre, 7. Aufl., 2004, p. 17-23; também ROXIN, Claus, Strafrecht..., p. 69-70; não referindo de forma expressa WESSELS, Johannes; BEULKE, Werner. Strafrecht, Allgemeiner Teil, 35. Aufl., 2005, p. 12 e ss.; também NAUCKE, Wolfgang. op. cit., p. 66-68.; igualmente, de forma expressa, HAFT, Fritjof, op.cit., p. 32-37; pontualmente ALBRECHT, Peter-Alexis. op.cit., p. 49-53.

44 Porém, como ressaltam RUDOLPHI/HORN/SAMSON/SCHREIBER. Systematischer Kommentar zum Strafgesetzbuch. $\S 1, \mathrm{I}, 3$, p. 27, estes preceitos, no Direito Penal vigente somente são concretizados em parte.

45 JESCHECK. Lehrbuch des Strafrechts. § 15, I, p. 77.

46 HASSEMER. Rechtssystem und Kodifikation. Die Bindung des Richters an das Gesetz. in: Einführung in Rechtsphilosophie und Rechtstheorie der Gegenwart. p. 194. No entanto, de modo oposto manifestava-se RADBRUCH. Einführung in die Rechtswissenschaft. p. 167, ao afirmar que a vinculação ao texto de lei por meio deste texto limitaria e por isso o tornaria completamente contra o autor, aproveitando métodos de interpretação que circulam o espírito do moderno Direito Penal e representam uma política jurídica de alto grau de risco.

47 HASSEMER. Rechtssystem und Kodifikation. Die Bindung des Richters an das Gesetz. p. 203.

48 Palazzo faz referência ao $§ 226$ a do StGB, não mais existente. O atual $§ 228$ refere: "quem causa uma lesão corporal com o consentimento da pessoa lesada, age ilicitamente somente se, apesar do consentimento, o fato violar os bons costumes".

49 Compare ROXIN, Claus. Strafrecht.... AT, 1992, p. 163; ademais, JESCHECK, Hans-Heinrich, op. cit., p. 215, ambos apontando o dispositivo citado como hipótese de regra exemplificativa; o sistema legal brasileiro também comporta esta possibilidade, como, por exemplo, no art. $121, \S 2 .^{\circ}$, I do CP ("ou outro motivo torpe"), a qual, apesar de ser questionável no que diz respeito à admissibilidade de interpretação analógica (posto que in malam partem), já foi objeto de discussão perante o Superior Tribunal de Justiça, no julgamento do HC 77309/SP, cuja ementa do julgado dispõe: "A qualificadora do motivo torpe para restar configurada, até pela própria redação do Código Penal, deve assemelhar-se ao crime de homicídio cometido "mediante paga ou promessa de recompensa", porquanto tem-se aí típica hipótese de interpretação analógica. Isso significa que o "outro motivo torpe" a que faz alusão a lei no final do dispositivo deve ter intensidade equiparada às hipóteses constantes no tipo.” (STJ, HC 77309/SP, Quinta Turma, Rel. Min. Felix Fischer, Julgado em 06/05/2008, LEXSTJ vol. 227 p. 324). No mesmo sentido, a decisão do REsp233797/GO, que dispõe: "O artigo 121, parágrafo $2^{\circ}$, inciso I, do Código Penal, após citar fórmulas casuísticas tais como o homicídio mediante paga ou promessa de pagamento, exige, alternativamente, para que incida, por meio de fórmula genérica, que o agente se impulsione à prática delitiva por "outro motivo torpe", reclamando, assim, motivação tão vil, ignóbil e abjeta quanto aquelas retratadas nas hipóteses previamente determinadas. Trata-se, como se vê, de hipótese de interpretação analógica ou intra legem.” (STJ, REsp233797/GO, Sexta Turma, Rel. Min. Hamilton Carvalhido, Julgado em 12/03/2002, DJ $19 / 12 / 2002$ p. 455).

50 Compare ALBRECHT, Peter-Alexis. op. cit., p. 56.

51 "O preceito do § 130, alínea 4 do StGB foi introduzido no Código Penal pela Lei de Modificação da Lei de Reunião e do Código Penal, de 24 de março de 2005 e entrou em vigência em 01 de abril de 2005 (BGBl I S. 969 970). Ele dispõe: (4) Será punido com pena privativa de liberdade de até 3 anos ou com multa, quem perturba, publicamente ou em uma reunião, a paz pública, de forma lesiva a dignidade da vítima, porque aprova, justifica ou enaltece atos de violência ou arbitrariedade nazista. O $§ 130$, alínea 4 do StGB não viola o mandato de certeza do Art. 103, alínea 2 da Lei Fundamental. Os elementos do tipo integrais são extraídos dele mesmo ou da relação com outras determinações do Código Penal, onde eles já teriam encontrado uma concretização suficientemente determinável.” (Tradução livre) 
52 Compare ALBRECHT, Peter-Alexis. op.cit., p. 56.

53 Compare BVerfGE 2BvR 1468/08.

54 O art. 103, alínea 2 da Lei Fundamental obriga o legislador a circunscrever os pressupostos de punibilidade de modo concreto, de forma que o âmbito de aplicação e o alcance dos tipos penais resultem do teor da lei ou, em todo caso, possam ser obtidos pela interpretação. Isso não exclui, no entanto, o emprego de conceitos que necessitem em certa medida da interpretação do juiz. Também no direito penal o legislador se encontra diante da necessidade de levar em conta a multiformidade da vida. Além disso, é devido a generalidade e a abstração inevitáveis das normas penais que no caso concreto se torna duvidoso se uma conduta ainda é abarcada ou não pelo tipo legal. Mas, em todo caso, o destinatário da norma deve poder prever a partir do preceito de lei se uma conduta é punível. Em casos limítrofes deve-se reconhecer deste modo pelo menos o risco de uma punição (stRspr, vgl. BVerfGE 92, 1 12).

55 Conforme ALBRECHT, Peter-Alexis. op. cit., p. 56.

56 Conforme ALBRECHT, Peter-Alexis. op .cit., p. 57.

57 ENGISCH, Karl. Introdução ao pensamento jurídico, p. 43.

\section{REFERÊNCIAS BIBLIOGRÁFICAS}

ALBRECHT, Peter-Alexis. Die vergessene Freiheit. Strafrechtsprinzipien in der europäischen Sicherheitsdebatte, 2003.

BAUMANN, Jürgen. Strafrecht. Allgemeiner Teil, 3. Aufl., 1964.

ENGISCH, Karl. Introdução ao pensamento jurídico. Lisboa: Fundação Calouste Guldenkian, 2001.

FEUERBACH, Paul Johann Anselm von. Lehrbuch des gemeinen in Deutschland gültigen peinlichen Rechts. 2. Aufl., Gießen: G. F. Heyer Verlag, 1803.

GOLDSCHMIDT, James. Begriff und Aufgabe eines Verwaltungsstrafrechts, in Deutsche Juristen-Zeitung, 1902, Nr. 09. GIACOMOLLI, Nereu José. 'O princípio da legalidade como limite do ius puniendi e proteção dos direitos fundamentais”, em STRECK, LL. Direito Penal em Tempos de Crise. Porto Alegre: Livraria do Advogado, 2007, p. 151 a 175. HAFT, Fritjof. Strafrecht, Allgemeiner Teil, 9. Aufl., München: Verlag C.H. Beck, p. 30.

HASSEMER, Winfried. Einführung in die Grundlagen des Strafrechts, 2. Aufl., München: Verlag C.H. Beck, 1990. HASSEMER. Rechtssystem und Kodifikation. Die Bindung des Richters an das Gesetz. in: Einführung in Rechtsphilosophie und Rechtstheorie der Gegenwart. p. 194.

JESCHECK. Lehrbuch des Strafrechts. München: Duncker \& Humblot, 1977.

LOPES JUNIOR, Aury; ALFLEN DA SILVA, Pablo Rodrigo. Breves apontamentos in memoriam a James Goldschmidt e a incompreendida concepção de processo como 'situação jurídica', in Revista de Processo, n. ${ }^{\circ} 176$, Out. 2009 , p. 349 e ss.

MAURACH, Reinhart; ZIPF, Heinz. Strafrecht. Allgemeiner Teil, Bd. I, 1977.

MEZGER, Edmund. Deutsches Strafrecht, Ein Grundriß, 3. Aufl., 1943.

NAUCKE, Wolfgang. Strafrecht. Eine Einführung, Berlin: Luchterhand, 2002.

OTTO, Harro, Grundkurs Strafrecht, Allgemeine Strafrechtslehre, 7. Aufl., Walter De Gruyter Verlag, 2004.

PALAZZO, Francesco; PAPA, Michele. Lezioni di diritto penal comparato. Torino: Giappichelli Editore, 2005.

RADBRUCH. Einführung in die Rechtswissenschaft.

ROXIN, Claus. Strafrecht. Allgemeiner Teil, Bd. I, München: Verlag C.H. Beck, 1992.

ROXIN, Claus. Derecho penal, parte general. Madri: Civitas, 1999.

RUDOLPHI/HORN/SAMSON/SCHREIBER. Systematischer Kommentar zum Strafgesetzbuch. München: Verlag Wolters Kluwer, 1973.

STERN, Klaus. Das Staatsrecht der Bundesrepublik Deutschland, Bd. I, München: C.H. Beck, 1980.

STRATENWERTH, Günter; KUHLEN, Lothar. Strafrecht, Allgemeiner Teil, Berlin: Heymanns Verlag, 2004

VOGEL, Hans-Joachim. "Die bundesstaatliche Ordnung des Grundgesetzes", em MAIHOFER, Werner et al.

Handbuch des Verfassungsrechts. Teil Zwei. München: Walter De Gruyter, 1995.

WESSELS, Johannes; BEULKE, Werner. Strafrecht, Allgemeiner Teil, 35. Aufl., 2005 


\section{ABREVIATURAS}

AE - Alternativ Entwurf (Projeto alternativo)

bayerischen StGB - bayerischen Strafgesetzbuch (Código Penal Bávaro)

BGBl. - Bundesgesetzblatt (Diário Oficial)

BRD - Bundesrepublik Deutschland (República Federal da Alemanha)

BVerfG - Bundesverfassungsgericht (Tribunal Constitucional Federal)

E - Entwurf (Projeto)

EGStGB - Einführungsgesetz zum Strafgesetzbuch (Lei de Introdução ao Código Penal)

GG - Grundgesetz (Lei Fundamental)

OWiG - Ordnungswidrigkeitengesetz (Lei dos ilícitos à ordem)

RStGB - Reichstrafgesetzbuch (Código Penal do Império)

StGB - Strafgesetzbuch (Código Penal alemão)

\author{
Av. Ipiranga, 6681, p. 11 \\ Partenon - 90619-900 \\ Porto Alegre - RS - Brasil \\ giacomolliagiacomolli.com
}

Nereu José Giacomolli

Doutor em Estudios de Actualidad Procesal Pela Universidad Complutense de MADRID.

PROFESSOR NO MESTRADO (DISCIPLINA DE PROCESSO PENAL CONTEMPORÂNEO) E DOUTORADO (DISCIPLINA DE SISTEMAS JURÍDICO-PENAIS COMPARADOS) EM CIÊNCIAS CRIMINAIS da Pontifícia Universidade Católica do Rio Grande DO SUL (PUC/RS)

Desembargador do Tribunal de JustiçA DO RIO GRANDE do Sul
Rua 24 de Outubro, 111, Conj. 501 Moinhos de Vento - 90510-002 Porto Alegre- RS - Brasil pabloalflenlaterra.com.br
Pablo Rodrigo Alflen da Silva Doutorando E MESTRE EM CIÊNCIAS CRIMINAIS PELA PONTIFíCIA Universidade Católica do Rio Grande do Sul (PUC/RS)

PROFESSOR DO DEPARTAMENTO DE CIÊNCIAS PENAIS DA FACULDADE DE DIREITO E DA PÓS-GRADUAÇÃO EM CIÊNCIAS PENAIS da Universidade Federal do Rio Grande do Sul (UFRGS)

Professor Concursado de Direito Penal e Processual Penal da Univates

Pesquisador credenciado aO CNPQ Advogado 